\title{
Clinical impact of diabetes mellitus in patients undergoing transcatheter aortic valve replacement
}

\author{
Anat Berkovitch 1,2,4, Amit Segev 1,4, Israel Barbash 1,4, Yoni Grossman 1,2,4, Elad Maor 1,3,4, Aharon Erez ${ }^{1,4}$, \\ Ehud Regev ${ }^{1,4}$, Noam Fink ${ }^{1,4}$, Israel Mazin ${ }^{1,4}$, Ashraf Hamdan ${ }^{1,4}$, Ilan Goldenberg ${ }^{1,4}$, Ilan Hay ${ }^{1,4}$, \\ Dan Spiegelstien ${ }^{1,4}$, Victor Guetta ${ }^{1,4}$ and Paul Fefer ${ }^{1,4^{*}}$
}

\begin{abstract}
Background: Diabetes mellitus (DM) and aortic stenosis (AS) are frequent findings in the elderly population. Data regarding the influence of DM on the outcomes of patients undergoing transcatheter aortic valve replacement (TAVR) due to AS are limited. The aim of this study was to examine the impact of DM on TAVR outcomes.

Methods: We investigated 443 patients with severe AS undergoing TAVR. Subjects were divided into insulin-dependent diabetic mellitus (IDDM) patients $(N=44)$, non-dependent insulin diabetic mellitus (NIDDM) patients $(\mathrm{N}=114)$ and non-diabetics $(N=285)$ of whom $31(74 \%), 86(79 \%)$ and $209(76 \%)$ respectively had trans-femoral TAVR. Periprocedural complications and outcomes were recorded according to the Valve Academic Research Consortium-2 criteria.

Results: Patients with IDDM as well as NIDDM demonstrated similar complication rates compared with non-diabetic patients, except for acute kidney injury (AKI) grade 3 [4 (2\%) and $3(3 \%)$ vs. $1(0.4 \%)$ respectively, p $=0.032$ ]. KaplanMeier survival analysis showed that DM, regardless of the type of treatment, was not associated with increased 2 years mortality (Log-rank p value 0.44 ). Multivariate cox regression analysis adjusted for age, gender, coronary artery disease, DM, AKI3, hypertension, chronic renal failure and peripheral vascular disease found that AKI3 was associated with increased risk of 2 years mortality $[\mathrm{HR}=7.35,95 \% \mathrm{Cl} 2.16-25.07, \mathrm{p}=0.001]$ whereas female gender was found as a protective factor [ $\mathrm{HR}=0.47,95 \% \mathrm{Cl} 0.28-0.8, \mathrm{p}=0.005]$, and DM was not associated with increased risk.
\end{abstract}

Conclusions: Following TAVR, DM patients seem to have similar peri-procedural and mid-term outcomes compared with patients without DM, while IDDM patients seem to suffer greater incidence of AKI. Further research in larger cohorts of patients is needed to validate our results.

Keywords: Diabetes mellitus, Trans-arterial valve replacement, Prognosis, Valvular disease

\section{Background}

Trans-catheter aortic valve replacement (TAVR), previously reserved for surgically high-risk patients with symptomatic aortic stenosis (AS), is now being utilized in a wider range of patients $[1,2]$. Patients treated with

\footnotetext{
*Correspondence: Paul.Fefer@sheba.health.gov.l

${ }^{1}$ Leviev Heart Center, Chaim Sheba Medical Center, 52621 Tel Hashomer, Israel

Full list of author information is available at the end of the article
}

TAVR have shown significant alleviation of symptoms and improved functional status [3, 4].

Diabetes mellitus (DM) and AS are both prevalent in the elderly population, and symptomatic AS has been found to be associated with DM [5]. Following cardiac surgery, patients with DM have been shown to suffer higher rates of renal dysfunction, need for blood transfusions and lung complications. Furthermore, DM patients undergoing TAVR have been shown to have less complications than DM patients undergoing surgical aortic valve replacement (SAVR) [6], and while mortality 
rates in patients undergoing TAVR have been shown to be equivalent [7] or reduced [8] compared with patients treated with SAVR, little is known about the impact of DM on the clinical outcomes of patients undergoing TAVR compared with the non-DM population. The aim of the current study was to investigate the clinical outcomes and complication rates among DM patients undergoing TAVR.

\section{Methods}

The study included 443 consecutive patients undergoing TAVR at the Sheba Medical Center between January 2008 and December 2014, of which 158 (36 \%) had DM. We analyzed separately DM patients treated with insulin (IDDM) (44 [28 \%]) and those treated either by diet or oral anti-diabetic agents (114 [72\%]). Candidates for TAVI were evaluated separately by an interventional cardiologist and by a cardiac surgeon. Cases were then discussed by the heart team which convenes on a weekly basis. Final decision to advise TAVR vs. SAVR was made by the heart team based on suitability for TAVI and surgical risk.

Baseline clinical data and chronic medication use were obtained from patients' electronic records. Patients with impaired renal function (creatinine $>1.2 \mathrm{mg} / \mathrm{dl}$ ) received peri-procedural balanced intravenous volume expansion with isotonic sodium chloride [9]. Peri-procedural complications were prospectively recorded according to the Valve Academic Research Consortium (VARC)-2 criteria. Mortality rates were ascertained with the Israeli Ministry of Interior mortality database through January 2015.

The study was approved by the local institutional review board (clinicaltrial.gov: SHEBA-13-0685-IB-CTIL).

\section{Definitions and outcome measures}

Patients were considered to have DM if they fulfilled at least one of the followings: (1) HbA1c $>6.5 \%$ at admission, (2) a random plasma glucose level higher than $200 \mathrm{mg} / \mathrm{dl}$ in the presence of symptoms, (3) use of glucose lowering medications. All DM patients had type 2 DM. Renal dysfunction was defined as a serum creatinine level greater than $1.4 \mathrm{mg} \%$.

The primary outcome of the current study was all cause mortality during a follow-up period of 2 years. Median follow-up time for the entire study population was 599 days. Secondary outcomes were defined as any VARC-2 defined peri-procedural complication.

\section{Statistical analysis}

Continuous data were compared with Student's t-test and one-way ANOVA. Categorical data were compared with the use of Pearson Chi square test.

Table 1 Baseline characteristics

\begin{tabular}{|c|c|c|c|c|}
\hline & \multirow[t]{2}{*}{ Non-diabetic $(\mathrm{N}=285)$} & \multicolumn{2}{|l|}{ Diabetic $(N=158)$} & \multirow[t]{2}{*}{ P-value } \\
\hline & & NIDDM (N = 114) & IDDM ( $N=44)$ & \\
\hline Age & $81.8 \pm 7.5$ & $79.8 \pm 7.5$ & $79.4 \pm 7.7$ & 0.016 \\
\hline Male & $128(46)$ & $53(46)$ & $23(52)$ & 0.71 \\
\hline Hemoglobin & $11.5(1.4)$ & $11.6(1.4)$ & $12.6(2.2)$ & 0.18 \\
\hline Glucose & $91(13)$ & $97(21)$ & $95(34)$ & 0.21 \\
\hline Renal dysfunction & $46(17)$ & $21(20)$ & $23(59)$ & $<0.001$ \\
\hline Hypertension & $232(84)$ & $103(94)$ & $34(83)$ & 0.032 \\
\hline Dyslipidemia & $199(72)$ & $90(83)$ & $34(85)$ & 0.036 \\
\hline Coronary artery disease & $124(46)$ & $48(45)$ & $24(60)$ & 0.22 \\
\hline CHF-NYHA class III-IV & $165(58)$ & $62(54)$ & $23(52)$ & 0.64 \\
\hline Atrial fibrillation/flutter & $66(27)$ & $29(28)$ & $13(33)$ & 0.71 \\
\hline Peripheral vascular disease & $33(12)$ & $13(12)$ & $6(15)$ & 0.85 \\
\hline Current smoker & $11(4)$ & $2(2)$ & $2(5)$ & 0.53 \\
\hline COPD & $41(15)$ & $19(18)$ & $11(28)$ & 0.13 \\
\hline$s / p C A B G$ & $57(21)$ & $22(21)$ & $10(26)$ & 0.8 \\
\hline $\mathrm{s} / \mathrm{pPCl}$ & $73(27)$ & $30(29)$ & $14(36)$ & 0.55 \\
\hline Pacemaker & $21(8)$ & $7(7)$ & $2(5)$ & 0.79 \\
\hline STS mortality & $5.3 \pm 3.7$ & $5.2 \pm 2.9$ & $7.6 \pm 5.6$ & 0.21 \\
\hline EUROSCORE 2 & $4.9 \pm 5.1$ & $4.7 \pm 5.3$ & $9.1 \pm 8.7$ & 0.16 \\
\hline $\mathrm{HbA} 1 \mathrm{c}$ & $5.7 \pm 0.43$ & $6.8 \pm 1.00$ & $7.9 \pm 1.47$ & $<0.001$ \\
\hline
\end{tabular}

All values are expressed as mean \pm SD or $\mathrm{N}(\%)$

NIDDM non-insulin dependent diabetes mellitus, IDDM insulin dependent diabetes mellitus, CHF congestive heart failure, NYHA New York Heart Association, COPD chronic obstructive lung disease, $C A B G$ coronary artery bypass surgery, $P C I$ percutaneous coronary intervention, STS Society of Thoracic Surgeons 
Kaplan-Meier survival analysis was used to descriptively show the association between DM and subsequent mortality. Multivariate cox regression adjusted for age, gender, coronary artery disease, DM, AKI3, hypertension, chronic renal failure and peripheral vascular disease was performed in order to find risk factors for mortality. Statistical significance was accepted for a two-sided $\mathrm{p}<0.05$. The statistical analyses were performed with IBM SPSS version 20.0 (Chicago, IL, USA).

\section{Results}

Of 443 patients included in the study 158 (36\%) had DM. These patients were compared with the 285 (64\%) patients without DM. Of the 158 diabetic patients 44 (28\%) were treated with insulin, while the others were treated either orally or by diet. Baseline clinical and laboratory characteristic by DM status are presented in Table 1. Notably, DM subjects were on average 2 years younger than non-diabetic patients and had a greater incidence of dyslipidemia. Subjects with IDDM had significantly greater incidence of baseline renal dysfunction. However, no other major differences in baseline characteristics were noted between groups, including STS score, EUROSCORE, NYHA class, or presence of coronary artery disease.

Procedural characteristics are summarized in Table 2. In most patients TAVR was performed via the trans-femoral approach (76\%) using conscious sedation (63\%). There were no differences between groups regarding the vascular approach, type of anesthesia, valve type or valve size used.

Diabetic patients demonstrated similar complication rates compared with non-diabetic patients (Table 3, Fig. 1), except for acute kidney injury (AKI) grade 3, which was more common in the IDDM group [1 (0.4\%) vs. 3 (3\%) and 2 (4\%), for non-diabetic, NIDDM, and IDDM respectively, $\mathrm{p}=0.032$ ]. No other significant differences were noted between groups.

The primary study outcome occurred in 108 (24.4\%) subjects. Kaplan-Meier survival analysis (Fig. 2) showed that the cumulative probability for mortality through 2 years of follow-up was not different between the groups (p-value Log rank $=0.439$ ), although there was a trend towards higher mortality among patients with IDDM.

Multivariate cox regression adjusted for age, gender, coronary artery disease, DM, AKI3, hypertension, chronic renal failure and peripheral vascular disease found that

Table 2 Procedural characteristics of TAVR patients

\begin{tabular}{|c|c|c|c|c|}
\hline & \multirow[t]{2}{*}{ Non-diabetic $(\mathrm{N}=285)$} & \multicolumn{2}{|l|}{ Diabetic $(\mathrm{N}=158)$} & \multirow[t]{2}{*}{ P-value } \\
\hline & & NIDDM (N = 114) & IDDM ( $\mathrm{N}=44)$ & \\
\hline \multicolumn{5}{|l|}{ Approach } \\
\hline Trans-femoral & $209(76)$ & $86(79)$ & $31(74)$ & \multirow[t]{3}{*}{0.53} \\
\hline Trans-apical & $49(18)$ & $19(17)$ & $9(21)$ & \\
\hline Other & $17(6)$ & $3(3)$ & $2(5)$ & \\
\hline \multicolumn{5}{|l|}{ Anesthesia } \\
\hline General & $89(39)$ & $34(34)$ & $12(36)$ & \multirow[t]{2}{*}{0.55} \\
\hline Conscious sedation & $140(61)$ & $66(66)$ & $21(61)$ & \\
\hline \multicolumn{5}{|l|}{ Valve type } \\
\hline SAPIEN XT & $109(41)$ & $48(45)$ & $18(45)$ & \multirow[t]{3}{*}{0.35} \\
\hline CoreValve & $159(58)$ & $55(51)$ & $20(50)$ & \\
\hline Other & $5(1)$ & $2(2)$ & $0(0)$ & \\
\hline \multicolumn{5}{|l|}{ Valve size } \\
\hline $23 \mathrm{~mm}$ & $52(20)$ & $19(18)$ & $9(24)$ & \multirow[t]{5}{*}{0.77} \\
\hline $25 \mathrm{~mm}$ & $0(0)$ & $1(1)$ & $0(0)$ & \\
\hline $26 \mathrm{~mm}$ & $106(41)$ & $45(44)$ & $13(35)$ & \\
\hline $29 \mathrm{~mm}$ & $93(36)$ & $34(33)$ & $13(35)$ & \\
\hline $31 \mathrm{~mm}$ & $6(2)$ & $4(4)$ & $2(5)$ & \\
\hline Valve-in-valve & $25(9)$ & $12(11)$ & $8(20)$ & 0.11 \\
\hline Procedural success & $262(98)$ & $103(97)$ & $38(100)$ & 0.59 \\
\hline Pre procedural EF & $55 \pm 12$ & $56 \pm 12$ & $54 \pm 12$ & 0.48 \\
\hline Pre-procedural moderate to severe MR & $74(26)$ & $26(23)$ & $10(23)$ & 0.76 \\
\hline Post-procedural moderate to severe AR & $37(13)$ & $14(12)$ & $2(5)$ & 0.27 \\
\hline
\end{tabular}

All values expressed as $\mathrm{N}(\%)$

NIDDM non-insulin dependent diabetes mellitus, IDDM insulin dependent diabetes mellitus 
Table 3 Cardiac complications

\begin{tabular}{|c|c|c|c|c|}
\hline \multirow[t]{2}{*}{ Complication } & \multirow[t]{2}{*}{ Non-diabetic ( $\mathrm{N}=285)$} & \multicolumn{2}{|l|}{ Diabetic $(N=158)$} & \multirow[t]{2}{*}{ P-value } \\
\hline & & NIDDM (N = 114) & $\operatorname{IDDM}(\mathrm{N}=44)$ & \\
\hline 30-days mortality & $12(4.2)$ & $3(2.6)$ & $2(4.5)$ & 0.73 \\
\hline 6-months mortality & $28(9.8)$ & $5(4.4)$ & $3(6.8)$ & 0.18 \\
\hline 1-year mortality & $39(13.7)$ & $11(9.6)$ & $4(9.1)$ & 0.43 \\
\hline Conversion to open surgery & $5(2)$ & $0(0)$ & $0(0)$ & 0.24 \\
\hline Unplanned cardiopulmonary bypass & $3(1)$ & $0(0)$ & $0(0)$ & 0.43 \\
\hline Coronary obstruction & $1(0.4)$ & $1(0.9)$ & $0(0)$ & 0.7 \\
\hline Cardiac tamponade & $8(3)$ & $4(4)$ & $1(2)$ & 0.91 \\
\hline Valve malpositioning & $11(4)$ & $7(6)$ & $1(2)$ & 0.5 \\
\hline Valve migration & $11(4)$ & $5(4)$ & $1(2)$ & 0.83 \\
\hline Peri-procedural MI ( $\leq 72 \mathrm{~h}$ post procedure) & $9(3)$ & $1(1)$ & $1(2)$ & 0.41 \\
\hline Spontaneous MI ( $\leq 72$ h post procedure) & $3(1)$ & $0(0)$ & $1(2)$ & 0.36 \\
\hline Transient atrio-ventricular block & $21(9)$ & $9(9)$ & $3(7)$ & 0.96 \\
\hline Permanent atrio-ventricular block & $41(17)$ & $18(18)$ & $5(12)$ & 0.72 \\
\hline Permanent pacemaker implantation & $55(22)$ & $24(23)$ & $8(19)$ & 0.86 \\
\hline New LBBB & $78(32)$ & $30(29)$ & $8(19)$ & 0.27 \\
\hline New RBBB & $3(1)$ & $1(1)$ & $0(0)$ & 0.77 \\
\hline New onset AF & $27(11)$ & $17(16)$ & $3(7)$ & 0.22 \\
\hline AF episode in patient with history of AF & $13(5)$ & $7(7)$ & $3(7)$ & 0.78 \\
\hline Heart failure post-procedure & $23(9)$ & $12(12)$ & $7(17)$ & 0.33 \\
\hline
\end{tabular}

All values expressed as $\mathrm{N}$ (\%)

NIDDM non-insulin dependent diabetes mellitus, IDDM insulin dependent diabetes mellitus, $M$ I myocardial infarction, $L B B B$ left bundle branch block, RBBB right bundle branch block, $A F$ atrial fibrillation

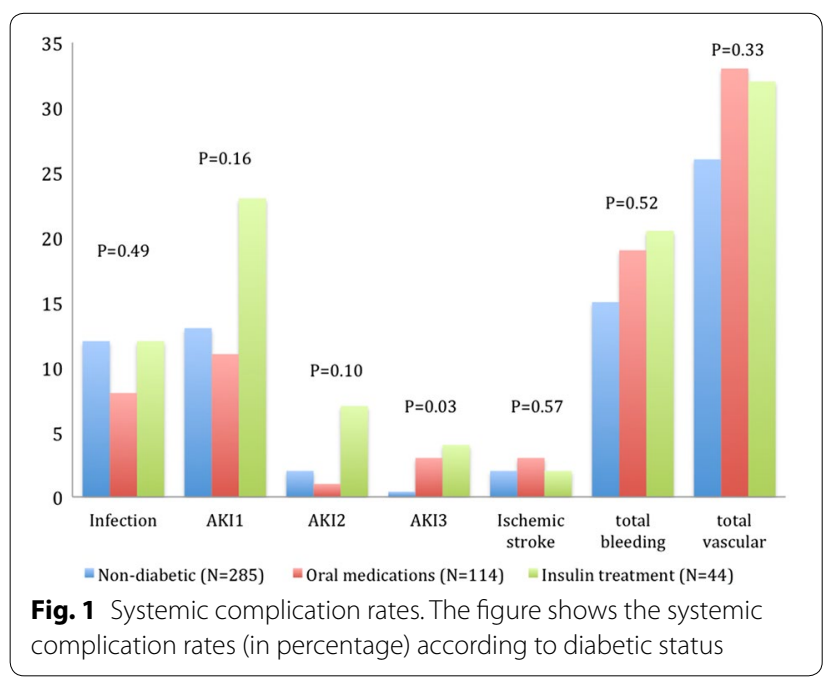

AKI3 $[\mathrm{HR}=7.35,95 \% \mathrm{CI} 2.16-25.07, \mathrm{p}=0.001]$ and peripheral vascular disease $[\mathrm{HR}=1.95,95 \%$ CI 1.12 $3.39, \mathrm{p}=0.019]$ were associated with increased risk of 2 -year mortality. Female gender was found to be a protective factor $[\mathrm{HR}=0.47,95 \% \mathrm{CI} 0.28-0.8, \mathrm{p}=0.005]$ and DM was not associated with increased risk (Table 4).

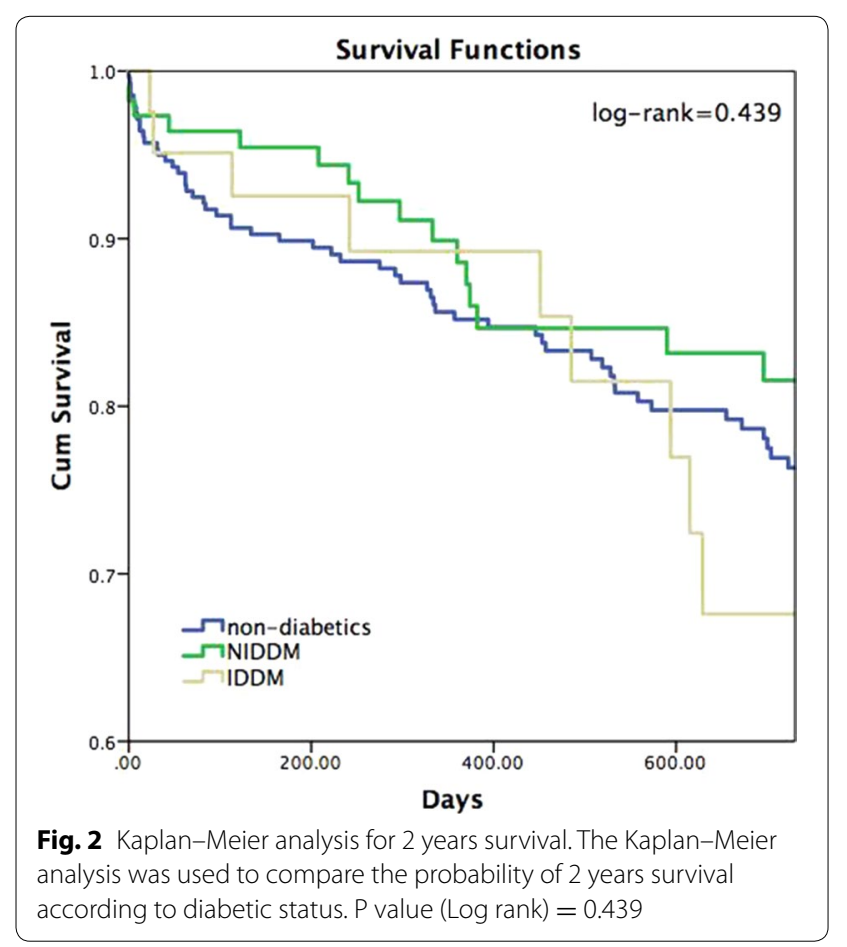


Table 4 Multivariate cox regression analysis for 2-year mortality

\begin{tabular}{lccl}
\hline Factor & HR & 95 \% confidence interval & P value \\
\hline Acute kidney injury 3 & 7.35 & $2.15-25.07$ & 0.001 \\
Peripheral vascular disease & 1.95 & $1.12-3.39$ & 0.019 \\
Chronic renal failure & 1.59 & $0.96-2.62$ & 0.07 \\
Diabetes mellitus & 0.83 & $0.49-1.40$ & 0.48 \\
Female gender & 0.47 & $0.28-0.80$ & 0.005 \\
\hline
\end{tabular}

Analysis was further adjusted for age, coronary artery disease and hypertension

We performed two additional sub-group analyses: first we analyzed outcomes of diabetic patients based on their HbA1C levels. Documented HbA1C levels during hospitalization were available in 105 patients with DM. Outcomes of well-controlled diabetic patients with HbA1C levels below $7 \%$ were equivalent to diabetic patients with HbA1C levels equal to or above $7 \%$ (Additional file 1 : Table S1). While numerically higher 1 year mortality rates were noted among DM patients with HbA1c levels above $7 \%$ compared with those below $7 \%$ [2 (4\%) vs 5 (9\%), $\mathrm{p}=0.23]$, this finding did not reach statistical significance, probably due to the relatively small group sample.

\section{Discussion}

The major finding of our study is that DM patients undergoing TAVR seem to have favorable outcomes with similar short and mid-term mortality rates compared with non-DM patients. Patients with IDDM in our study had greater incidence of renal insufficiency at baseline and both DM groups suffered from increased rate of AKI after the procedure, however other peri-procedural complications occurred equally among DM and non-DM patients.

Up to $40 \%$ of older individuals have DM [10]. Elderly DM patients have unique characteristics and suffer from higher cardiovascular disease rates compared to younger DM patients [11]. However, limited data exists with respect to the effect of DM on mortality after TAVR. Our findings are supported by two previous studies: Minha et al. [12] followed 499 patients who had TAVR and concluded that DM was not associated with poor outcome. However in this study patients were not divided according to treatment type (insulin vs. oral hypoglycemic agents). Conrotto et al. [13] examined 511 patients undergoing TAVR, of whom 150 had DM, and also found no difference regarding the short and mid-term effect of DM on mortality rates in these patients. A number of studies suggest differential outcomes in DM patients: Tamburino et al. [14], in a study of 663 patients after TAVR found a higher incidence of DM among those who died and argued that DM at baseline may be associated with increased mortality.
However this study failed to compare baseline characteristics between DM and non-DM subjects and is inherently biased in that it examined characteristics of patients who died following the procedure. Similarly, Puls et al. [15] reported poor outcome among 108 DM patients. However, in contrast to our series, most TAVR were performed by the transapical approach and their total mortality rates were much higher than those found in our cohort, suggesting that these patients had greater baseline risk.

While we failed to demonstrate statistically significant differences in mortality rates between IDDM and NIDDM patients, Kaplan-Meier analysis did suggest a trend towards worse outcomes among IDDM subjects. However, our sample size is inadequate to properly address mortality between groups.

Acute kidney injury rates were significantly higher among DM patients, especially the IDDM group. This finding is not surprising given the higher CRF rates at baseline. Previous studies have found CRF and AKI injury to be predictors for in-hospital mortality, 30 days mortality and 1 year mortality post-TAVR [16-19]. Our findings are similar to those mentioned above. However, and despite having higher rates of AKI, IDDM patients in our study did not demonstrate significantly higher mortality rates when compared with NIDDM patients or with non-diabetic patients. A possible explanation for this discrepancy may be the small number of IDDM or the relatively small number of events (AKI) in the population which failed to reach statistical significance.

\section{Limitations}

This paper is based on a moderately sized cohort emanating from a single center. The limited number of enrolled patients does not allow assessment of specific outcome measures and sub-group analysis and avoids the potential for a propensity-matched evaluation or use of post hoc comparisons between the three groups due to high-risk for type II errors. Larger cohorts are necessary to further assess the prognostic impact of diabetes mellitus on outcome after TAVR.

\section{Conclusions}

Diabetic patients seem to have favorable short- and midterm outcomes following TAVR which are similar to patients without DM. Insulin treated DM patients may have greater incidence of AKI, and appropriate peri-procedural strategies should be employed to minimize this risk in these patients.

\section{Additional file}

Additional file 1: Table S1. Complication rates based on $\mathrm{HbA} 1 \mathrm{c}$ levels. 


\section{Abbreviations}

DM: diabetes mellitus; TAVR: trans-catheter aortic valve replacement; AKI: acute kidney injury; VARC: Valve Academic Research Consortium; NYHA: New York Heart Association.

\section{Authors' contributions}

$A B, P F$ : have made substantial contributions to conception and design, acquisition of data and analysis and interpretation of data; have been involved in drafting the manuscript and revising it critically for important intellectual content; have given final approval of the version to be published; agree to be accountable for all aspects of the work in ensuring that questions related to the accuracy or integrity of any part of the work are appropriately investigated and resolved. AS, IB, AH, IG, IH, DS, VG: have made substantial contributions to conception and design, acquisition of data and analysis and interpretation of data; have been involved in revising it critically for important intellectual content; have given final approval of the version to be published; agree to be accountable for all aspects of the work in ensuring that questions related to the accuracy or integrity of any part of the work are appropriately investigated and resolved. YG, EM, AE, ER, NF, IM: have made substantial contributions to acquisition of data; have been involved in drafting the manuscript; have given final approval of the version to be published; agree to be accountable for all aspects of the work in ensuring that questions related to the accuracy or integrity of any part of the work are appropriately investigated and resolved. All authors read and approved the final manuscript.

\section{Author details}

${ }^{1}$ Leviev Heart Center, Chaim Sheba Medical Center, 52621 Tel Hashomer, Israel. ${ }^{2}$ Department of Internal Medicine D, Chaim Sheba Medical Center, Tel Hashomer, Israel. ${ }^{3}$ Pinchas Borenstein Talpiot Medical Leadership Program, Chaim Sheba Medical Center, Tel Hashomer, Israel. ${ }^{4}$ Sackler School of Medicine, Tel-Aviv University, Tel Aviv, Israel.

\section{Author disclosure statement}

Amit Segev is a proctor for Medtronic and Edwards Lifesciences.

\section{Compliance with ethical guidelines}

\section{Competing interests}

The authors declare that they have no competing interests.

Received: 20 June 2015 Accepted: 15 September 2015 Published online: 01 October 2015

\section{References}

1. Gotzmann M, Pljakic A, Bojara W, Lindstaedt M, Ewers A, Germing A, Mügge A. Transcatheter aortic valve implantation in patients with severe symptomatic aortic valve stenosis-predictors of mortality and poor treatment response. Am Heart J. 2011;162(238-245):e1.

2. Poliacikova P, Cockburn J, Pareek N, James R, Lee L, Trivedi U, De Belder A, Hildick-smith D. Prognostic impact of pre-existing right ventricular dysfunction on the outcome of transcatheter aortic valve implantation. J Invasive Cardiol. 2013;25:142-5.

3. Webb JG, Pasupati S, Humphries K, Thompson C, Altwegg L, Moss R, Sinhal A, Carere RG, Munt B, Ricci D, Ye J, Cheung A, Lichtenstein SV. Percutaneous transarterial aortic valve replacement in selected high-risk patients with aortic stenosis. Circulation. 2007;116:755-63.

4. Grube E, Schuler G, Buellesfeld L, Gerckens U, Linke A, Wenaweser P, Sauren B, Mohr FW, Walther T, Zickmann B, Iversen S, Felderhoff T, Cartier R, Bonan R. Percutaneous aortic valve replacement for severe aortic stenosis in high-risk patients using the second- and current third-generation self-expanding CoreValve prosthesis. Device success and 30-day clinical outcome. J Am Coll Cardiol. 2007;50:69-76.

5. Falcão-Pires I, Hamdani N, Borbély A, Gavina C, Schalkwijk CG, van der Velden J, van Heerebeek L, Stienen GJM, Niessen HWM, Leite-Moreira AF, Paulus WJ. Diabetes mellitus worsens diastolic left ventricular dysfunction in aortic stenosis through altered myocardial structure and cardiomyocyte stiffness. Circulation. 2011;124:1151-9.
6. Lindman BR, Pibarot P, Arnold SV, Suri R, McAndrew TC, Maniar HS, Zajarias A, Kodali S, Kirtane AJ, Thourani VH, Tuzcu EM, Svensson LG, Waksman R, Smith CR, Leon MB. Transcatheter versus surgical aortic valve replacement in patients with diabetes and severe aortic stenosis at high risk for surgery: an analysis of the PARTNER trial. J Am Coll Cardiol. 2013;63:1090-9.

7. Smith CR, Leon MB, Mack MJ, Miller DC, Moses JW, Svensson LG, Tuzcu EM, Webb JG, Fontana GP, Makkar RR, Williams M, Dewey T, Kapadia S, Babaliaros V, Thourani VH, Corso P, Pichard AD, Bavaria JE, Herrmann HC, Akin JJ, Anderson WN, Wang D, Pocock SJ. Transcatheter versus surgical aortic-valve replacement in high-risk patients. N Engl J Med. 2011;364:2187-98.

8. Reardon $\mathrm{M}$, et al. A randomized comparison of self-expanding transcatheter and surgical aortic valve replacement in patients with severe aortic stenosis deemed at increased risk for surgery 2-year outcomes. In: Presented at ACC, San Diego, CA. 2015.

9. Fliser D, Laville M, Covic A, Fouque D, Vanholder R, Juillard L, Van Biesen W. A European Renal Best Practice (ERBP) position statement on the kidney disease improving global outcomes (KDIGO) clinical practice guidelines on acute kidney injury: part 1: definitions, conservative management and contrast-induced nephropathy. Nephrol Dial Transpl. 2012;27:4263-72.

10. Sinclair A, Morley JE, Rodriguez-Mañas L, Paolisso G, Bayer T, Zeyfang A, Bourdel-Marchasson I, Vischer U, Woo J, Chapman I, Dunning T, Meneilly G, Rodriguez-Saldana J, Gutierrez Robledo LM, Cukierman-Yaffe T, Gadsby R, Schernthaner G, Lorig K. Diabetes mellitus in older people: position statement on behalf of the International Association of Gerontology and Geriatrics (IAGG), the European Diabetes Working Party for Older People (EDWPOP), and the International Task Force of Experts in Diabetes. J Am Med Dir Assoc. 2012;13:497-502.

11. Bethel MA, Sloan FA, Belsky D, Feinglos MN. Longitudinal incidence and prevalence of adverse outcomes of diabetes mellitus in elderly patients. Arch Intern Med. 2007;167:921-7.

12. Minha S, Magalhaes MA, Barbash IM, Ben-Dor I, Escarcega RO, Okubagzi PG, Baker NC, Chen F, Torguson R, Suddath WO, Staler LF, Pichard AD, Waksman R. The impact of diabetes mellitus on outcome of patients undergoing transcatheter aortic valve replacement. IJC Metab Endocr. 2015. doi:10.1016/j.ijcme.2015.05.023.

13. Conrotto F, D'Ascenzo F, Giordana F, Salizzoni S, Tamburino C, Tarantini G, Presbitero P, Barbanti M, Gasparetto V, Mennuni M, Napodano M, Rossi ML, La Torre M, Ferraro G, Omedè P, Scacciatella P, Marra WG, Colaci C, Biondi-Zoccai G, Moretti C, D'Amico M, Rinaldi M, Gaita F, Marra S. Impact of diabetes mellitus on early and midterm outcomes after transcatheter aortic valve implantation (from a multicenter registry). Am J Cardiol. 2014;113:529-34.

14. Tamburino C, Capodanno D, Ramondo A, Petronio AS, Ettori F, Santoro G, Klugmann S, Bedogni F, Maisano F, Marzocchi A, Poli A, Antoniucci D, Napodano M, De Carlo M, Fiorina C, Ussia GP. Incidence and predictors of early and late mortality after transcatheter aortic valve implantation in 663 patients with severe aortic stenosis. Circulation. 2011;123:299-308.

15. Puls M, Bleckmann A, Jacobshagen C, Danner BC, Hasenfuss G, Seipelt $R$, Schillinger W. Diabetes increases short- and long-term mortality after transcatheter aortic valve implantation (TAVI). Dtsch Med Wochenschr. 2014;139:822-8.

16. Elhmidi Y, Bleiziffer S, Piazza N, Hutter A, Opitz A, Hettich I, Kornek M, Ruge H, Brockmann G, Mazzitelli D, Lange R. Incidence and predictors of acute kidney injury in patients undergoing transcatheter aortic valve implantation. Am Heart J. 2011;161:735-9.

17. Nuis RJM, Van Mieghem NM, Tzikas A, Piazza N, Otten AM, Cheng J, van Domburg RT, Betjes M, Serruys PW, de Jaegere PPT. Frequency, determinants, and prognostic effects of acute kidney injury and red blood cell transfusion in patients undergoing transcatheter aortic valve implantation. Catheter Cardiovasc Interv. 2011;77:881-9.

18. Sinning J-M, Ghanem A, Steinhäuser H, Adenauer V, Hammerstingl C, Nickenig $G$, Werner N. Renal function as predictor of mortality in patients after percutaneous transcatheter aortic valve implantation. JACC Cardiovasc Interv. 2010;3:1141-9.

19. Barbash IM, Ben-Dor I, Dvir D, Maluenda G, Xue Z, Torguson R, Satler LF, Pichard AD, Waksman R. Incidence and predictors of acute kidney injury after transcatheter aortic valve replacement. Am Heart J. 2012;163:1031-6. 